\title{
Simultaneous quantification and inhibitory effect on LDL oxidation of the traditional Korean medicine, Leejung-tang
}

\author{
Chang-Seob Seo, Ohn Soon Kim, Yeji Kim and Hyeun-Kyoo Shin*
}

\begin{abstract}
Background: Leejung-tang (LJT) is a traditional Korean herbal medicine for the treatment of gastrointestinal disorders. In this study, we performed quantification analysis of five marker components, liquiritin (1), ginsenoside Rg1 (2), ginsenoside Rb1 (3), glycyrrhizin (4), and 6-gingerol (5) in LJT using a high performance liquid chromatography-photodiode array (HPLC-PDA). In addition, we investigated the inhibitory effect on low-density lipoprotein (LDL) oxidation by the LJT sample.

Methods: Compounds 1-5 were separated within 35 min using a Gemini $C_{18}$ column. The mobile phase used gradient elution with 1.0\% (v/V) aqueous acetic acid (A) and 1.0\% ( $/ \mathrm{V})$ acetic acid in acetonitrile (B). The flow rate was $1.0 \mathrm{~mL} / \mathrm{min}$ and the detector was a photodiode array (PDA) set at $203 \mathrm{~nm}, 254 \mathrm{~nm}$, and $280 \mathrm{~nm}$. The inhibitory effect on LDL oxidation conduct an experiment on thiobarbituric acid reactive substance (TBARS) assay, relative electrophoretic mobility (REM) assay, and electrophoresis of ApoB fragmentation of LJT.

Results: Calibration curves of compounds $1-5$ showed good linearity $\left(r^{2} \geq 0.9995\right)$ in different concentration ranges. The recoveries of compounds $1-5$ were in the range of $98.90-103.39 \%$, with relative standard deviations (RSD) below 3.0\%. The RSDs (\%) of intra-day and inter-day precision were $0.10-1.08 \%$ and $0.29-1.87 \%$, respectively. The inhibitory effect of LJT on $\mathrm{Cu}^{2+}$-induced LDL oxidation was defined by TBARS assay $\left(\mathrm{IC}_{50}: 165.7 \mu \mathrm{g} / \mathrm{mL}\right)$ and REM of oxLDL (decrease of $50 \%$ at $127.7 \mu \mathrm{g} / \mathrm{mL}$ ). Furthermore $L J T$ reduced the fragmentation of ApoB of oxLDL in a dose-dependent manner.

Conclusions: The established HPLC-PDA method will be helpful to improve quality control of LJT. In addition, LJT is a potential LDL oxidation inhibitor.
\end{abstract}

Keywords: Simultaneous quantification, Leejung-tang, HPLC-PDA, LDL oxidation, Traditional Korean medicine

\section{Background}

Traditional herbal medicines commonly consist of various herbs and have been used to prevent and treat a variety of diseases. Moreover, they also have few side effects. Leejung-tang (LJT, Lizhong-tang in Chinese) is one of the traditional Korean herbal medicines consisting of four herbal medicines, Ginseng Radix Alba, Zingiberis Rhizoma, Glycyrrhizae Radix et Rhizoma, and Atractylodis Rhizoma Alba. LJT has been used to treat various symptoms such as vomiting, stomach pain, chronic gastritis,

\footnotetext{
* Correspondence: hkshin@kiom.re.kr

Herbal Medicine Formulation Research Group, Herbal Medicine Research

Division, Korea Institute of Oriental Medicine, Yuseongdae-ro 1672, Yuseong-gu, Daejeon 305-811, Korea
}

(C) 2014 Seo et al.; licensee BioMed Central Ltd. This is an open access article distributed under the terms of the Creative Commons Attribution License (http://creativecommons.org/licenses/by/2.0), which permits unrestricted use, distribution, and reproduction in any medium, provided the original work is properly cited. and ulceration for a long time in Eastern countries [1]. Pharmacological studies of LJT have shown antiallergic [2,3], antitumor, immunomodulatory [4], acute toxicity [5], and gastroprotective [6] effects. Recently, the single herbs of LJT, including Ginseng Radix Alba [7], Zingiberis Rhizoma [8], and Glycyrrhizae Radix et Rhizoma [9] were reported to have an inhibitory effects against atherosclerosis. However, studies on the simultaneous analysis and inhibitory effect on low-density lipoprotein (LDL) oxidation by LJT have not been reported. Therefore, we performed simultaneous determination of five marker components — ginsenoside Rg1 (2) and ginsenoside Rb1 (3) in Ginseng Radix Alba, 6-gingerol (5) in Zingiberis Rhizoma, and liquiritin (1) and glycyrrhizin (4) in Glycyrrhizae 
<smiles>O=C1CC(c2ccc(OC(O)C(O)C(O)C(O)CO)cc2)Oc2cc(O)ccc21</smiles>

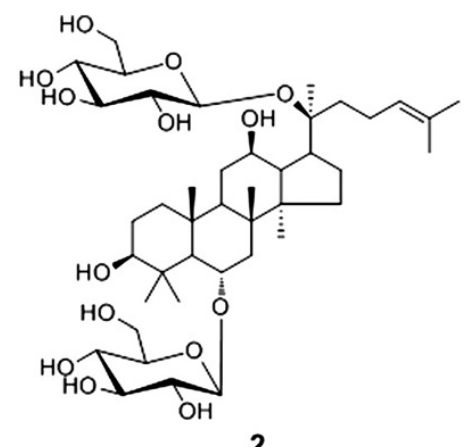

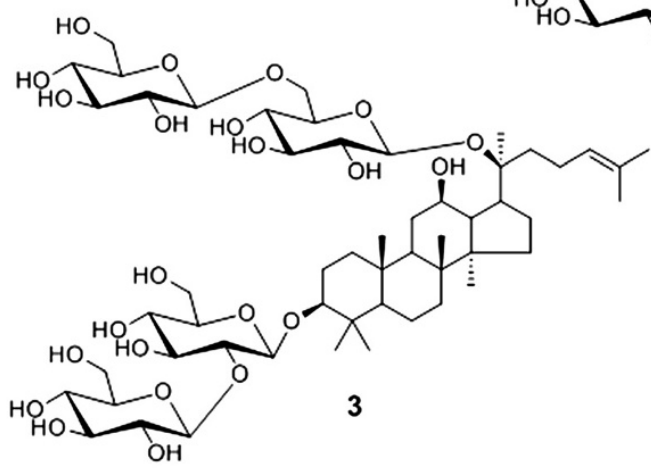
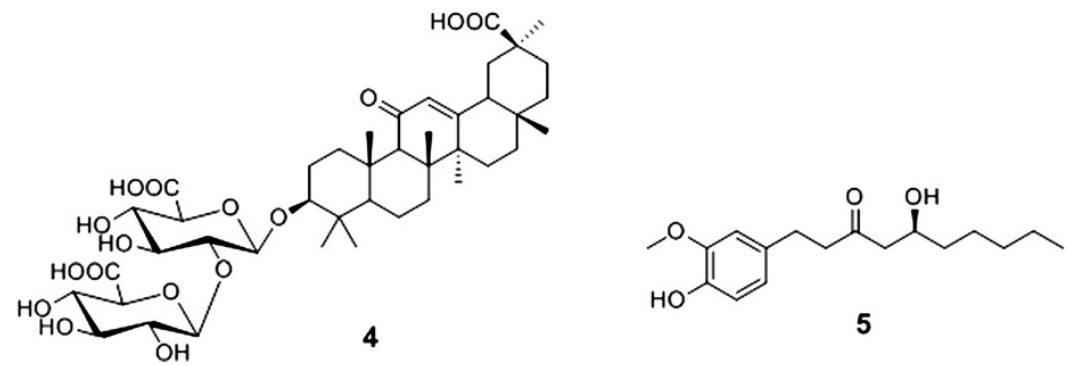

Figure 1 Chemical structures of compounds $1-5$ in LJT.

Radix et Rhizoma - for quality control of LJT using the high-performance liquid chromatography-photodiode array (HPLC-PDA) method. The chemical structures of these compounds are shown in Figure 1. In addition, we evaluated the inhibitory effect on $\mathrm{Cu}^{2+}$-induced LDL oxidation by the LJT sample.

\section{Methods}

\section{Chemicals and materials}

Ginsenoside Rg1, ginsenoside Rb1, glycyrrhizin, and 6-gingerol were purchased from Wako (Osaka, Japan).

Table 1 Crude components of LJT

\begin{tabular}{cccc}
\hline Latin name & Amount (g) & Supplier & Location \\
\hline Ginseng Radix Alba & 7.50 & Omniherb & Geumsan, Korea \\
Atractylodis Rhizoma & 7.50 & Omniherb & China \\
Glycyrrhizae Radix & 3.75 & HMAX & China \\
Zingiberis Rhizoma & 7.50 & Omniherb & Yeongcheon, Korea \\
Crudus & & & \\
Total amount & 26.25 & & \\
\hline
\end{tabular}

Liquiritin was obtained from NPC BioTechnology Inc. (Daejeon, Korea). The purities of all reference compounds were $\geq 98.0 \%$ according to HPLC analysis. HPLC-grade methanol, acetonitrile, and water were obtained from J.T. Baker (Phillipsburg, NJ, USA). Glacial acetic acid was of analytical reagent grade and procured from Junsei (Tokyo, Japan). The crude herbal medicines from Ginseng Radix Alba, Zingiberis Rhizoma, Glycyrrhizae Radix et Rhizoma, and Atractylodis Rhizoma Alba were purchased from Omniherb (Yeongcheon, Korea) and HMAX (Jecheon, Korea). The origin of each herbal medicine was taxonomically confirmed by Prof. Je Hyun Lee, Dongguk University, Gyeongju, Korea. Voucher specimens (2008-KE19-1 through KE19-4) have been deposited at the Basic Herbal Medicine Research Group, Korea Institute of Oriental Medicine.

\section{Apparatus and conditions}

The HPLC analysis was performed using a Shimadzu LC-20A (Shimadzu Co., Kyoto, Japan), which consisted of a pump (LC-20AT), on-line degasser (DGU-20A 3 ), 

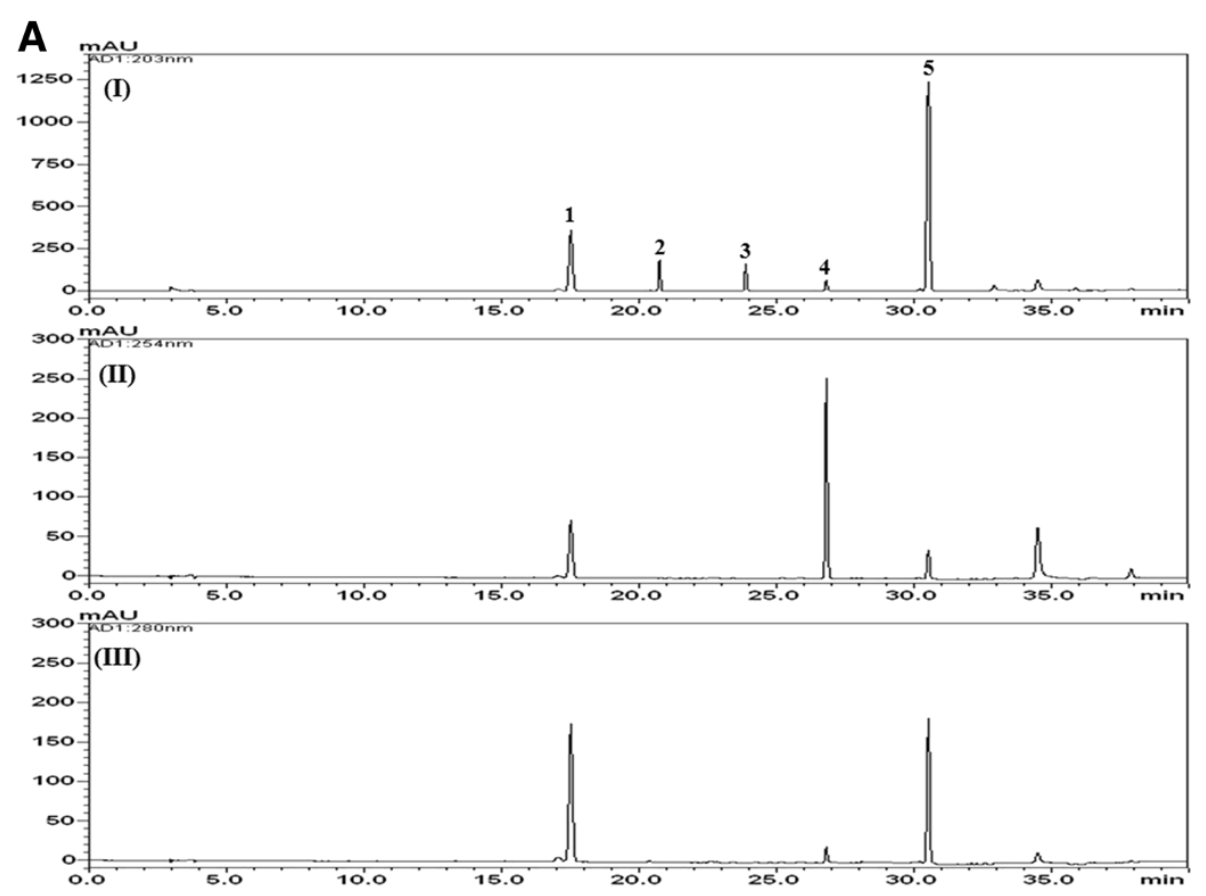

B
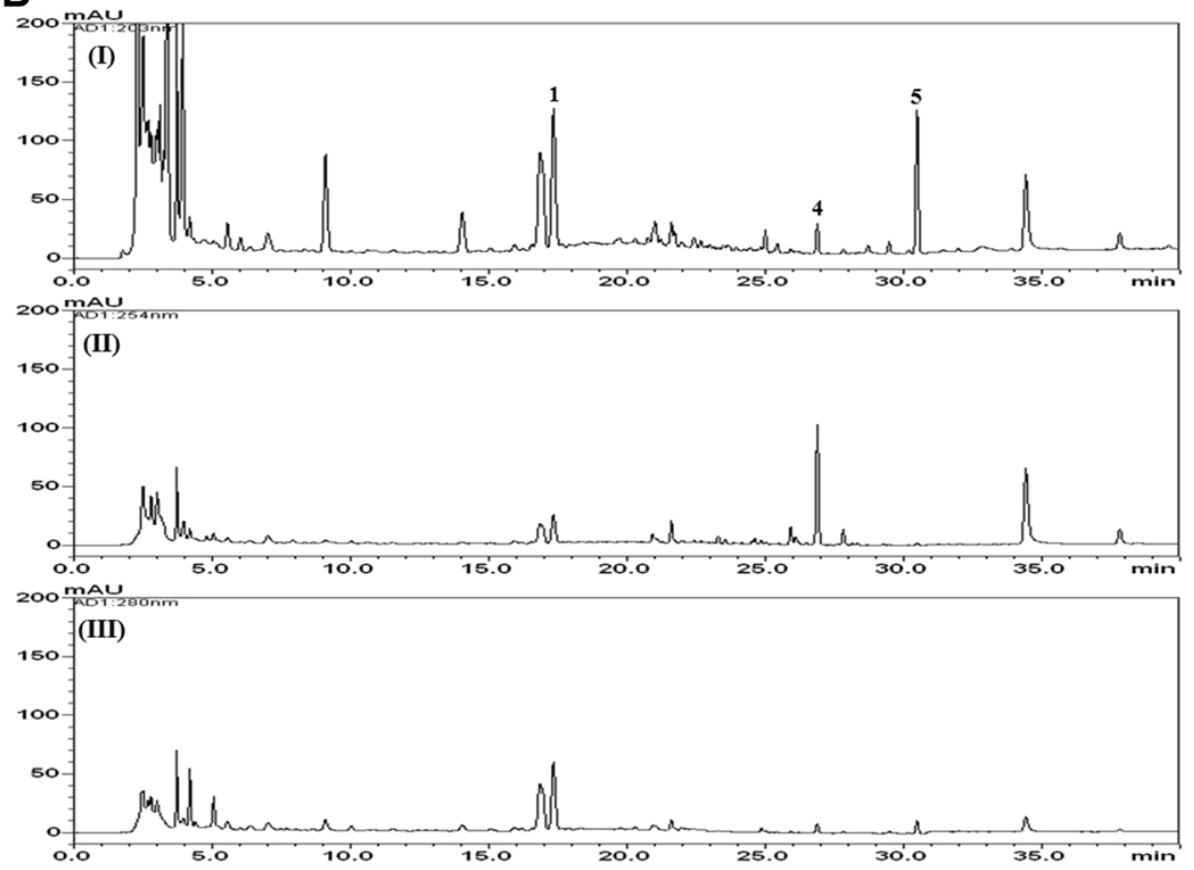

Figure 2 HPLC chromatogram of a standard mixtures (A) and LJT samples (B) at 203 nm (I), 254 nm (II), and 280 nm (III). Liquiritin (1), ginsenoside Rg1 (2), ginsenoside Rb1 (3), glycyrrhizin (4), and 6-gingerol (5).

column oven (CTO-20A), autosampler (SIL-20 AC), and PDA detector (SPD-M20A). The data were processed with LCsolution software (Version 1.24, Shimadzu, Kyoto, Japan). The analytes were separated on a Phenomenex Gemini $\mathrm{C}_{18}$ column $(250 \times 4.6 \mathrm{~mm}, 5 \mu \mathrm{m}$, Torrance, CA, USA) maintained at $40^{\circ} \mathrm{C}$. The gradient elution of mobile phases A (1.0\% v/v aqueous acetic acid) and B (acetonitrile with $1.0 \% \mathrm{v} / \mathrm{v}$ acetic acid) was conducted as follows: $15-20 \%$ B for $0-10 \mathrm{~min}, 20-70 \%$ B for $10-30 \mathrm{~min}$, $70-100 \%$ B for $30-40 \mathrm{~min}, 100 \%$ B for $40-45 \mathrm{~min}$, and $100-15 \% \mathrm{~B}$ for $45-50 \mathrm{~min}$. The flow rate was $1.0 \mathrm{~mL} / \mathrm{min}$ and injection volume was $10 \mu \mathrm{L}$. The 


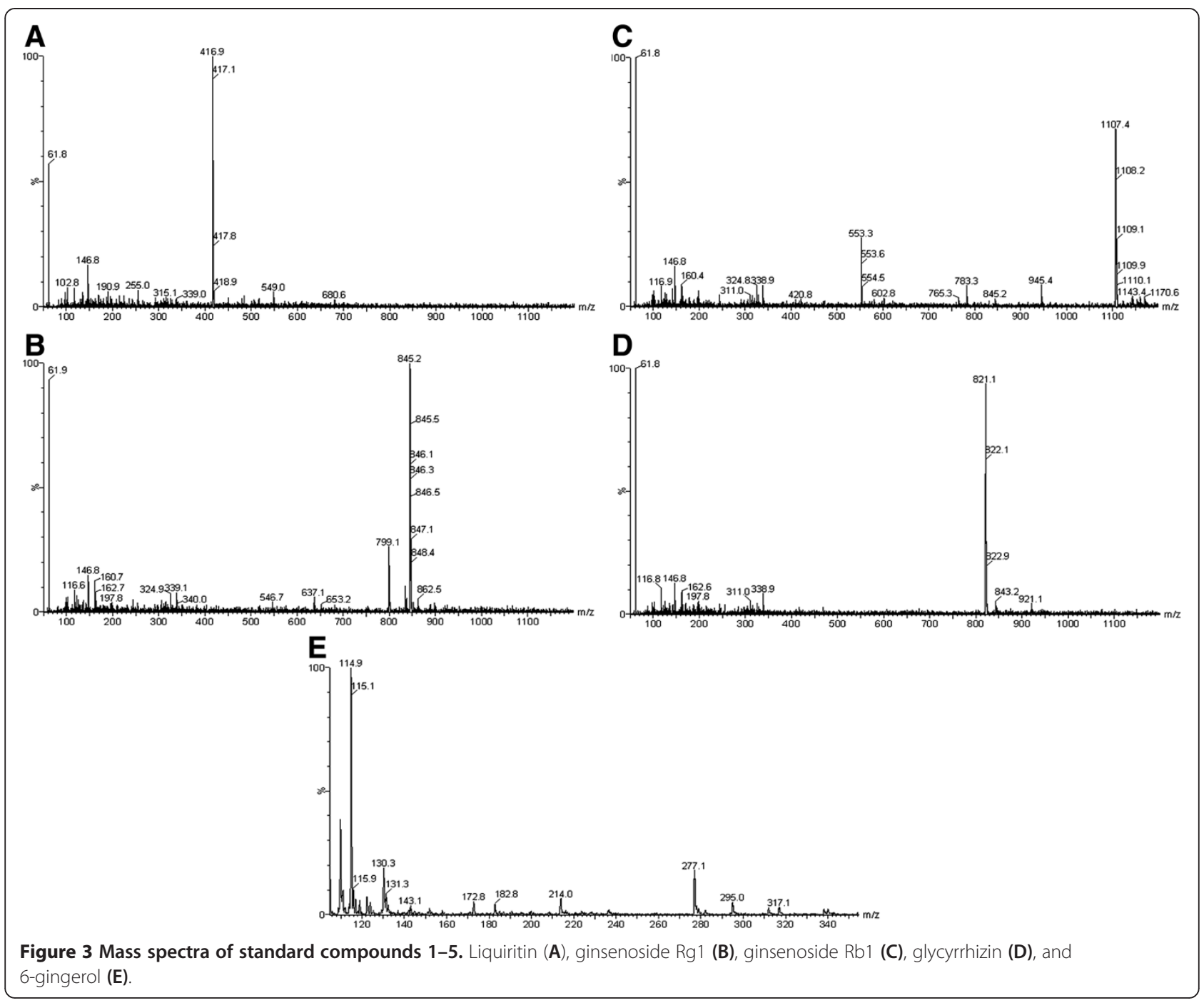

PDA detector was monitored at $203 \mathrm{~nm}, 254 \mathrm{~nm}$, and $280 \mathrm{~nm}$.

The mass spectrometer was operated using a Waters triple quadruple mass spectrometer equipped with electrospray ionization (ESI) source. The MS conditions were as follows: capillary voltage, $3.3 \mathrm{kV}$; extractor voltage, $3 \mathrm{~V}$; RF lens voltage, $0.3 \mathrm{~V}$; source temperature, $120^{\circ} \mathrm{C}$; desolvation temperature, $300^{\circ} \mathrm{C}$; desolvation gas,
$600 \mathrm{~L} / \mathrm{h}$; cone gas, $50 \mathrm{~L} / \mathrm{h}$; collision gas, $0.14 \mathrm{~mL} / \mathrm{min}$. Data acquisition was processed by Waters MassLynx software (version 4.1, Milford, MA, USA).

\section{Preparation of standard solutions}

The reference compounds $\mathbf{1 - 5}$ were accurately weighed and dissolved in methanol at a concentration of

Table 2 Calibration curves, LODs, LOQs, and the detected ions of the five marker compounds

\begin{tabular}{|c|c|c|c|c|c|c|}
\hline Compound & Linear range $(\mu \mathrm{g} / \mathrm{mL})$ & Regression equation $^{a}$ & Correlation coefficient $\left(r^{2}\right)$ & $\operatorname{LOD}^{b}(\mu \mathrm{g} / \mathrm{mL})$ & $\mathrm{LOQ}^{c}(\mu \mathrm{g} / \mathrm{mL})$ & Detected ion \\
\hline 1 & $1.00-500.00$ & $y=15003.57 x-8421.59$ & 1.0000 & 0.26 & 0.87 & {$[\mathrm{M}-\mathrm{H}]^{-}$} \\
\hline 2 & $5.00-500.00$ & $y=3944.65 x-9262.82$ & 0.9995 & 0.60 & 2.00 & {$[\mathrm{M}-\mathrm{H}]^{-}$} \\
\hline 3 & $5.00-500.00$ & $y=1979.05 x+4406.77$ & 0.9999 & 2.44 & 8.13 & {$[\mathrm{M}-\mathrm{H}]^{-}$} \\
\hline 4 & $1.00-500.00$ & $y=7952.91 x-4715.75$ & 1.0000 & 0.52 & 1.72 & {$[\mathrm{M}-\mathrm{H}]^{-}$} \\
\hline 5 & $5.00-500.00$ & $y=5737.29 x-3255.18$ & 1.0000 & 0.48 & 1.59 & {$[\mathrm{M}+\mathrm{H}]^{+}$} \\
\hline
\end{tabular}

a: peak area (mAU) of compounds; $x$ : concentration $(\mu \mathrm{g} / \mathrm{mL})$ of compounds. 
Table 3 Recoveries for the assay of three investigated compounds in LJT

\begin{tabular}{|c|c|c|c|c|c|}
\hline Analytes & Original amount $(\mu \mathrm{g} / \mathrm{mL})$ & Spiked amount $(\mu \mathrm{g} / \mathrm{mL})$ & Found amount $(\mu \mathrm{g} / \mathrm{mL})$ & Recovery $^{\mathrm{a}} \pm$ SD (\%) & RSD (\%) \\
\hline & & 12.00 & 57.15 & $101.43 \pm 1.07$ & 1.05 \\
\hline \multirow[t]{3}{*}{$1^{b}$} & 44.98 & 25.00 & 70.10 & $100.89 \pm 1.06$ & 1.05 \\
\hline & & 50.00 & 95.64 & $101.32 \pm 1.19$ & 1.18 \\
\hline & & 24.00 & 137.08 & $101.19 \pm 2.11$ & 2.09 \\
\hline \multirow[t]{3}{*}{4} & 112.79 & 60.00 & 173.09 & $100.50 \pm 1.48$ & 1.47 \\
\hline & & 120.00 & 236.86 & $103.39 \pm 2.62$ & 2.53 \\
\hline & & 3.00 & 16.34 & $101.34 \pm 0.92$ & 0.91 \\
\hline \multirow[t]{2}{*}{5} & 13.30 & 8.00 & 21.22 & $98.90 \pm 0.69$ & 0.69 \\
\hline & & 15.00 & 28.37 & $100.41 \pm 1.11$ & 1.10 \\
\hline
\end{tabular}

${ }^{\mathrm{a}}$ Recovery $(\%)=($ Found amount - Original amount $) /$ Spiked amount $\times 100$.

${ }^{\mathrm{b}}$ The compound numbers are the same as in Figure 1.

$1,000 \mu \mathrm{g} / \mathrm{mL}$. Stock solutions were stored below $4^{\circ} \mathrm{C}$ and underwent serial dilution with methanol before analysis.

\section{Preparation of sample solutions}

Dried crude herbals from Ginseng Radix Alba, Zingiberis Rhizoma, Glycyrrhizae Radix et Rhizoma, and Atractylodis Rhizoma Alba (Table 1, $10.0 \mathrm{~kg} ; 26.25 \mathrm{~g} \times 381$ ) were mixed and extracted in a 10 -fold mass of distilled water at $100^{\circ} \mathrm{C}$ for $2 \mathrm{~h}$. After filtration, the solution was evaporated to dryness and freeze-dried $(2.5 \mathrm{~kg})$. The yield of LJT extract was 20.8\%. The powdered LJT (200 mg) was extracted with $20 \mathrm{~mL}$ of $50 \%$ methanol for $90 \mathrm{~min}$ by sonication. The solution was filtered through a $0.2 \mu \mathrm{m}$ membrane filter (Woongki Science, Seoul, Korea) before HPLC analysis.

\section{Calibration curve, limits of detection (LOD), and quantification (LOQ)}

Each calibration curve was obtained by assessment of peak areas from standard solutions in the following concentration ranges: compounds $\mathbf{1}$ and 4, 1.00$500.00 \mu \mathrm{g} / \mathrm{mL}$ and compounds 2, 3, and 5, 5.00$500.00 \mu \mathrm{g} / \mathrm{mL}$. Stock solutions of reference compounds 1-5 were diluted with methanol to assess LOD and
LOQ values. The LOD and LOQ data were determined at signal-to-noise $(\mathrm{S} / \mathrm{N})$ ratios of 3 and 10 , respectively.

\section{Precision and accuracy}

Intra-day and inter-day precisions were determined using a standard addition method to prepare spiked samples, employing both standards and controls. To confirm the repeatability, six replicates using the mixed standard solutions were measured and evaluated. The relative standard deviation (RSD) of peak areas and retention times of each compound were used to evaluate the method repeatability. Accuracy tests, which were evaluated by a recovery test, were performed by adding three different concentration levels (low, middle, and high) of reference compounds 1-5 to $200 \mathrm{mg}$ of LJT sample. This test was evaluated using the calibration curve.

\section{Determination of LDL oxidation \\ Oxidation of $L D L$ by $\mathrm{CuSO}_{4}$}

We performed oxidation of LDL using $\mathrm{CuSO}_{4}$-mediated method [10]. LDL samples $(500 \mu \mathrm{g}$ protein $/ \mathrm{mL}$, Biomedical Technologies, Stoughton, MA, USA) were prepared at $37^{\circ} \mathrm{C}$ in a medium containing $10 \mathrm{mM}$ phosphate buffer $(\mathrm{pH} 7.4)$ and various concentrations of sample. After $5 \mathrm{~min}$, the

Table 4 The precision and accuracy of the analytical results $(n=5)$

\begin{tabular}{|c|c|c|c|c|c|c|c|}
\hline \multirow{2}{*}{ Compound } & \multirow{2}{*}{$\begin{array}{c}\text { Fortified } \\
\text { conc. }(\mu \mathrm{g} / \mathrm{mL})\end{array}$} & \multicolumn{3}{|c|}{ Intra-day } & \multicolumn{3}{|c|}{ Inter-day } \\
\hline & & Observed Conc. ( $\mu \mathrm{g} / \mathrm{mL})$ & Precision (\%) & Accuracy (\%) & Observed Conc. ( $\mu \mathrm{g} / \mathrm{mL})$ & Precision (\%) & Accuracy (\%) \\
\hline & 12.00 & 11.94 & 1.08 & 99.46 & 12.06 & 0.92 & 100.46 \\
\hline \multirow[t]{3}{*}{1} & 25.00 & 25.47 & 0.16 & 101.88 & 24.84 & 1.33 & 99.37 \\
\hline & 50.00 & 49.78 & 0.10 & 99.56 & 50.06 & 0.29 & 100.13 \\
\hline & 24.00 & 23.69 & 1.06 & 98.70 & 24.04 & 1.87 & 100.17 \\
\hline \multirow[t]{3}{*}{4} & 60.00 & 60.00 & 0.67 & 100.00 & 58.88 & 1.26 & 98.13 \\
\hline & 120.00 & 120.06 & 0.14 & 100.05 & 120.55 & 0.36 & 100.46 \\
\hline & 3.00 & 3.03 & 0.72 & 100.83 & 3.04 & 0.85 & 101.45 \\
\hline \multirow[t]{2}{*}{5} & 8.00 & 8.18 & 0.84 & 102.22 & 7.91 & 1.05 & 98.83 \\
\hline & 15.00 & 14.90 & 0.24 & 99.34 & 15.04 & 0.29 & 100.28 \\
\hline
\end{tabular}


Table 5 The amount of marker compounds $1-5$ in the LJT sample $(n=3)$

\begin{tabular}{cccc}
\hline \multirow{2}{*}{ Compound } & \multicolumn{3}{c}{ Amount (mg/g) } \\
\cline { 2 - 4 } & Mean & SD & RSD (\%) \\
\hline $\mathbf{1}$ & 4.50 & 0.02 & 0.42 \\
$\mathbf{2}$ & $\mathrm{ND}^{\mathrm{a}}$ & - & - \\
$\mathbf{3}$ & $\mathrm{ND}$ & - & - \\
$\mathbf{4}$ & 11.10 & 0.02 & 0.18 \\
$\mathbf{5}$ & 1.33 & 0.01 & 0.39 \\
\hline${ }^{\mathrm{a} N D: \text { not detected. }}$ & & &
\end{tabular}

oxidation was initiated by the addition of $\mathrm{CuSO}_{4}(25 \mu \mathrm{M})$. After $6 \mathrm{~h}$ oxidation, lipid peroxidation, electrophoretic mobility, and Apo B fragmentation of the LDL were measured as described below.

\section{Determination of thiobarbituric acid reactive substance (TBARS)}

Lipid peroxidation of LDL was estimated by the determination of the level of malondialdehyde (MDA) using a TBARS assay kit (BioAssay Systems, CA, USA) according to the manufacturer's protocols [11]. After oxidation, $50 \mu \mathrm{g}$ of LDLs was mixed with $200 \mu \mathrm{L}$ of thiobarbituric acid (TBA) and incubated at $100^{\circ} \mathrm{C}$ for $30 \mathrm{~min}$. After completing the reaction, the absorbance at $535 \mathrm{~nm}$ was measured using a microplate reader.

\section{Relative electrophoretic mobility (REM) assay}

The electrophoretic mobility of LDLs was measured using agarose gel ( $0.8 \%$ agarose in TAE buffer) electrophoresis and Coomassie Brilliant Blue R-250 staining. Electrophoresis was performed at $100 \mathrm{~V}$ for $30 \mathrm{~min}$. REM was defined as the ratio of the distances migrated from the origin by oxLDL versus native LDL [12].

\section{Electrophoresis of ApoB fragmentation}

After oxidation, $20 \mu \mathrm{g}$ of LDLs were denatured with 3\% sodium dodecylsulfate (SDS), 10\% glycerol, and 5\% 2mercaptoethanol at $100^{\circ} \mathrm{C}$ for $5 \mathrm{~min}$. SDS-polyacrylamide gel electrophoresis (6\% SDS-PAGE) was performed to detect the ApoB fragmentation. The electrophoresis proceeded at $100 \mathrm{~V}$ for $6 \mathrm{~h}$. After the electrophoresis, the gel was stained with Coomassie Brilliant Blue R-250 to visualize ApoB of LDLs [13].

\section{Statistical analysis}

Statistical evaluation of the results was performed using a one-way analysis of variance (ANOVA) followed by Dunnett's multiple comparison test using GraphPad InStat 3.05 software (Graphpad Software Inc, CA, USA).

\section{Results and discussion}

\section{Optimization of extraction methods}

The extraction conditions were optimized to obtain a satisfactory extraction efficiency examining extraction method (ultra-sonication and shaking), extraction solvent (0\%, 50\%, $70 \%$, and $90 \%$ methanol, $\mathrm{v} / \mathrm{v})$, and extraction time $(10,20$, $30,60,90$, and $120 \mathrm{~min}$ ). By comparing the peak area of the target compounds for different conditions, the most satisfactory conditions were selected as ultra-sonication with $50 \%$ methanol for $90 \mathrm{~min}$.

\section{Optimization of chromatographic conditions}

We obtained satisfactory separation chromatograms using two mobile phase systems with gradient elution. Quantitation was achieved using PDA detection at $203 \mathrm{~nm}$ for compounds 2 and 3, 254 nm for compound 4, and $280 \mathrm{~nm}$ for compounds $\mathbf{1}$ and $\mathbf{5}$, based on retention time and UV spectra compared with those of the standards. Using the optimized chromatography conditions, the five compounds eluted within $35 \mathrm{~min}$ and afforded good specificity without interference from other compounds. Representative HPLC chromatograms of standards and the extract are shown in Figure 2.

The MS conditions were optimized in full scan mode using the reference compounds (Figure 3). Compounds 1-4 were detected in the negative ion mode $[\mathrm{M}-\mathrm{H}]^{-}$at $\mathrm{m} / \mathrm{z}$ 417.1, $\mathrm{m} / \mathrm{z}$ 799.1, $\mathrm{m} / \mathrm{z} 1107.4$, and $\mathrm{m} / \mathrm{z}$ 821.2, respectively. Compound 5 was detected using the positive ion mode $[\mathrm{M}+\mathrm{H}]^{+}$with $\mathrm{m} / z 295.0$ (Table 2).

\section{Linearity, range, LOD, and LOQ}

The linearity of the peak area $(y)$ versus concentration $(x, \mu \mathrm{g} / \mathrm{mL})$ curve for each component was used to calculate the amount of each main component in LJT. The calibration curves for compounds 1-5 showed good

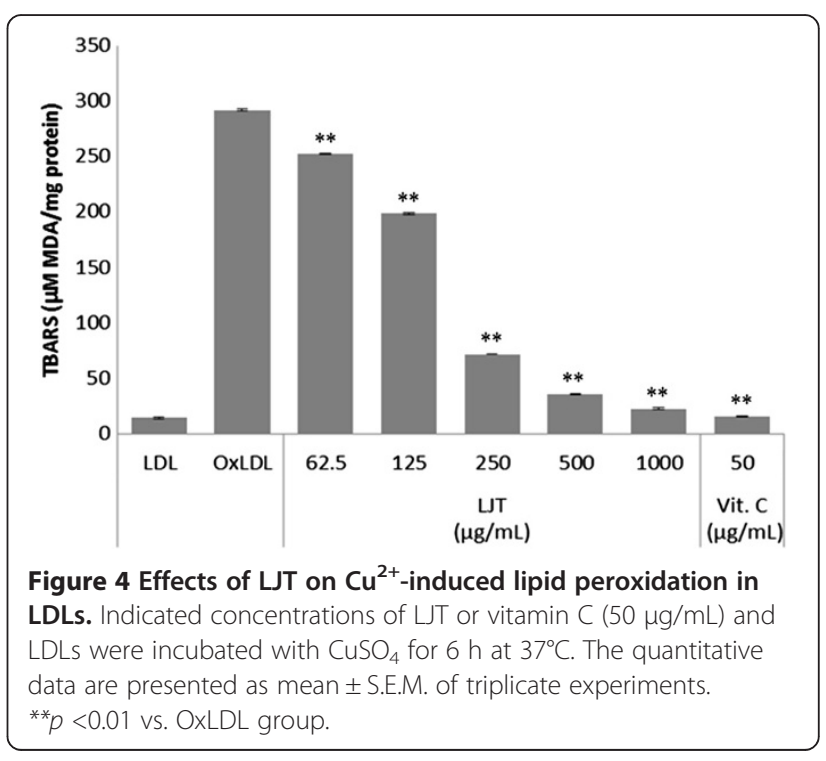




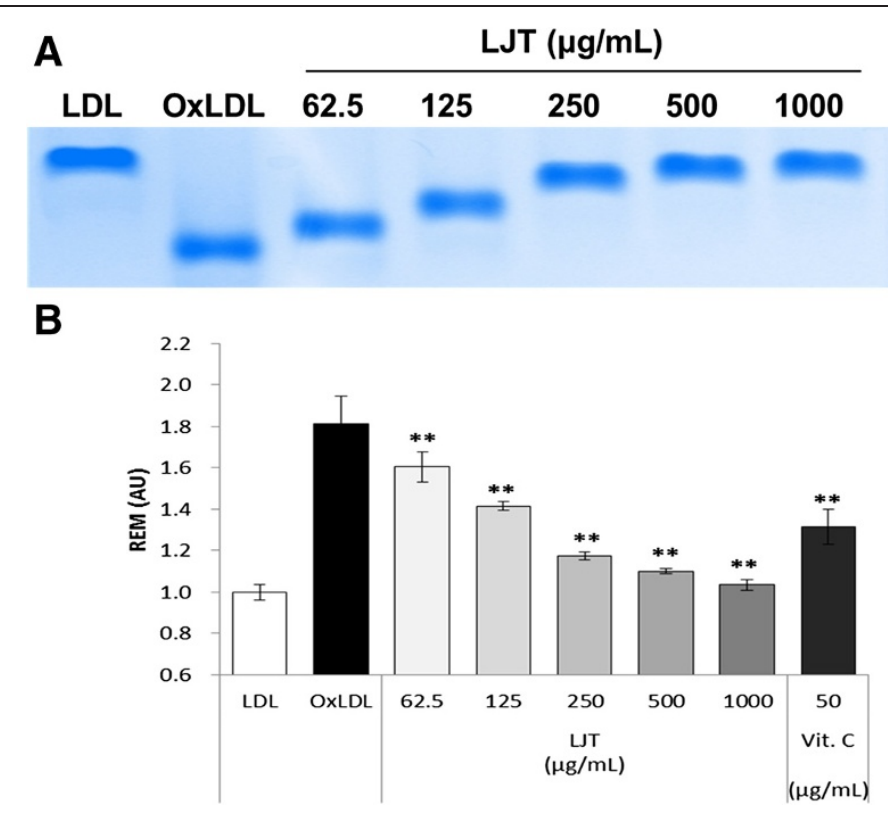

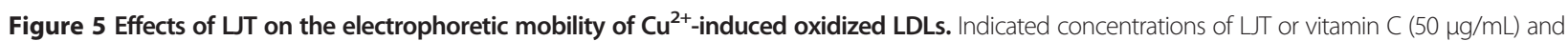
LDLs were incubated with $\mathrm{CuSO}_{4}$ for $6 \mathrm{~h}$ at $37^{\circ} \mathrm{C}$. The electrophoretic mobility of LDLs was measured using agarose gel electrophoresis. (A) The stained gel is representative of two independent experiments. (B) Relative electrophoretic mobilities, indicating the distances moved from the origin, were calculated and presented.

linearity $\left(r^{2} \geq 0.9995\right)$. The LODs and LOQs were less than $2.44 \mu \mathrm{g} / \mathrm{mL}$ and $8.13 \mu \mathrm{g} / \mathrm{mL}$, respectively (Table 2 ).

\section{Accuracy and precision}

The recoveries of the results are shown in Table 3. The recovery of compounds $\mathbf{1 - 5}$ was in the range of 98.90 $103.39 \%$, and the RSD values were less than $2.53 \%$. Repeatability for all analytes was better than RSD $0.44 \%$ for peak responses and better than RSD 0.09\% for retention times (data not shown). Thus, the HPLC assay showed good repeatability under optimized conditions. The precisions of intra-day and inter-day variation of investigated compounds 1-5 in LJT were less than $1.08 \%$ and $1.87 \%$, respectively (Table 4).

\section{Sample analysis}

For the simultaneous quantification of the five marker compounds in traditional Korean herbal medicine, LJT, the newly established HPLC-PDA method was used by comparing the retention time with reference standards. The amounts of the five identified compounds in LJT varied from not detected to $11.10 \mathrm{mg} / \mathrm{g}$ (Table 5).

\section{Effect of LTT on $\mathrm{Cu}^{2+}$-mediated oxidation of LDL}

In this study, we evaluated the anti-atherosclerotic potential of LJT by their ability to inhibit $\mathrm{Cu}^{2+}$-mediated LDL oxidation models. LDL is the major carrier in the blood stream. Oxidative modification of LDL has been known to play a key role during early atherosclerosis. Protection of LDL from oxidation should be an effective strategy to prevent the development or progression of atherosclerosis [14-16]. Liquiritin (1) and glycyrrhizin (4) in Glycyrrhizae Radix et Rhizoma and 6-gingerol (5) in Zingiberis Rhizoma were detected from LJT by HPLC analysis (Table 5). The root extracts of Glycyrrhiza glabra (licorice) decreased the susceptibility of LDL to oxidation $[17,18]$. The extract of Zingiberis Rhizoma reduced cell-mediated oxidation of LDL [12] and gingerol isolated from Zingiber was shown to inhibit AAPH- or hemin-mediated LDL oxidation [19].

In the present study, the effect of LJT on $\mathrm{Cu}^{2+}$-mediated oxidation of LDL was determined by several methods. First, the degree of LDL oxidation was evaluated by TBARS assay. Lipid peroxidation was quantified

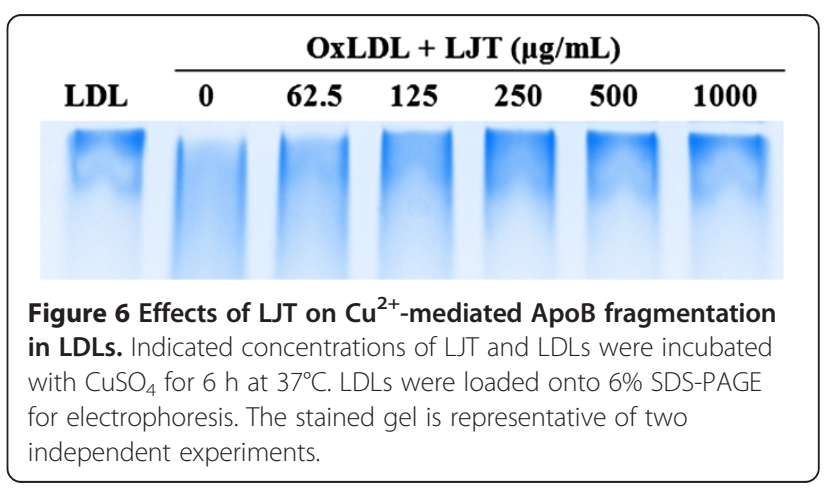


by measuring MDA, the degradation by-products [20]. As shown in Figure 4, when LDL was incubated with $\mathrm{CuSO}_{4}$ for $6 \mathrm{~h}$, a significant increase in TBARS was detected. In contrast, LJT significantly reduced the amount of TBARS formed in a concentration-dependent manner $\left(\mathrm{IC}_{50}: 165.7 \mu \mathrm{g} / \mathrm{mL}\right)$. Alteration of agarose gel electrophoretic mobility reflects the increase in negative charge of LDL particles that occurs during oxidation [12]. When the oxidation was carried out in the presence of LJT, the increased electrophoretic mobility of oxidized LDL was significantly reduced (Figure 5 ). Because fragmentation of ApoB can also be caused by oxidative modification of LDL [21], the inhibitory effect of LJT on LDL oxidation was also evaluated by fragmentation of ApoB using electrophoretic analysis on SDS-PAGE. The ApoB band was observed on native LDL that had been incubated without $\mathrm{CuSO}_{4}$, but this band disappeared when $\mathrm{LDL}$ was incubated with $\mathrm{CuSO}_{4}$ for $6 \mathrm{~h}$ at $37^{\circ} \mathrm{C}$. In the presence of LJT, the fragmentation of ApoB of LDL was concentration-dependent inhibited (Figure 6). These data suggest that LJT has an inhibitory effect on LDL oxidation.

\section{Conclusions}

A simple and accurate HPLC-PDA method has been developed for simultaneous separation and determination of fiver major components in the traditional Korean herbal medicine, LJT. The developed method showed good linearity, precision, and accuracy to evaluate the quality of LJT. The proposed method will be valuable for quality control of LJT. In addition, we evaluated the inhibitory effect on LDL oxidation of LJT at a concentration of $1,000 \mu \mathrm{g} / \mathrm{mL}$ and the results showed inhibitory activity. Consequently, LJT may have an inhibitory effect on LDL oxidation.

\section{Competing interest}

The authors declare that they have no competing interest.

\section{Authors' contributions}

CSS and HKS conceived and designed the experiments and manuscript preparation. OSK and YK conducted the experiments against the LDL oxidation effects. All authors read and approved the final manuscript.

\section{Acknowledgments}

This research was supported by a grant (no. K13030) from the Korea Institute of Oriental Medicine.

Received: 7 May 2013 Accepted: 5 December 2013

Published: 3 January 2014

\section{References}

1. Hur J: Donguibogam. Seoul: Namsandang; 2007:382.

2. Seo HY, Han JK, Kim YH: The effect of Lizhongtang on the suppression of Th2 differentiation by IFN-r response in IGE hyperproduction and atopic dermatitis-like skin lesions induced in NC/Nga mouse. J Kor Orient Pediatr 2009, 23:1-22.

3. Seo HY, Han JK, Kim YH: Therapeutic effects of Yijungtang on atopic dermatitis-like skin lesions of NC/Nga mouse induced by mite antigen. J Kor Orient Pediatr 2011, 25:1-27.
4. Ha JY, Lee J: Experiment on the antitumor and immunomodulatory effects of Gagamijungtang in BALB/c mice. Kor J Orient Med Pathol 1998, 12:73-81.

5. Jung YP, Hwang YH, Lee JH, Yim NH, Cho WK, Ma JY: A study on the acute toxicity of Leejung-tang (Lizhong-tang) and fermented Leejung-tang (Lizhong-tang) extract in ICR mice. Kor J Herbology 2012, 27:95-100.

6. Shin IS, Lee MY, Lim HS, Seo CS, Ha HK, Shin HK: Gastroprotective effects of Leejung-tang, an oriental traditional herbal formula, on ethanolinduced acute gastric injury in rats. Afr J Tradit Complement Altern Med 2013, 10:316-323.

7. Li J, Xie ZZ, Tang YB, Zhou JG, Guan YY: Ginsenoside-Rd, a purified component from panax notoginseng saponins, prevents atherosclerosis in apoE knockout mice. Eur J Pharmacol 2011, 10:104-110.

8. Fuhrman B, Rosenblat M, Hayek T, Coleman R, Aviram M: Ginger extract consumption reduces plasma cholesterol, inhibits LDL oxidation and attenuates development of atherosclerosis in atherosclerotic, apolipoprotein E-deficient mice. J Nutr 2000, 130:1124-1131.

9. Visavadiya NP, Soni B, Dalwadi N: Evaluation of antioxidant and antiatherogenic properties of Glycyrrhiza glabra root using in vitro models. Int J Food Sci Nutr 2009, 60(Suppl 2):135-149.

10. Barnhart RL, Busch SJ, Jackson RL: Concentration-dependent antioxidant activity of probucol in low density lipoproteins in vitro: probucol degradation precedes lipoprotein oxidation. J Lipid Res 1989, 30:1703-1710.

11. Buege JA, Aust SD: Microsomal lipid peroxidation. Methods Enzymol 1978 52:302-310.

12. Sparks DL, Phillips MC: Quantitative measurement of lipoprotein surface charge by agarose gel electrophoresis. J Lipid Res 1992, 33:123-130.

13. Miura S, Watanabe J, Tomita T, Sano M, Tomita I: The inhibitory effects of tea polyphenols (flavan-3-ol derivatives) on $\mathrm{Cu} 2+$ mediated oxidative modification of low density lipoprotein. Biol Pharm Bull 1994, 17:1567-1572.

14. Steinberg $D$, Witztum JL: Is the oxidative modification hypothesis relevant to human atherosclerosis? Do the antioxidant trials conducted to date refute the hypothesis? Circulation 2002, 105:2107-2111.

15. Stocker R, Keaney JF Jr: Role of oxidative modifications in atherosclerosis. Physiol Rev 2004, 84:1381-1478.

16. Jialal I, Grundy SM: Effect of dietary supplementation with alphatocopherol on the oxidative modification of low density lipoprotein. J Lipid Res 1992, 33:899-906.

17. Vaya J, Belinky PA, Aviram M: Antioxidant constituents from licorice roots: isolation, structure elucidation and antioxidative capacity toward LDL oxidation. Free Radic Biol Med 1997, 23:302-313.

18. Belinky PA, Aviram M, Fuhrman B, Rosenblat M, Vaya J: The antioxidative effects of the isoflavan glabridin on endogenous constituents of LDL during its oxidation. Atherosclerosis 1998, 137:49-61.

19. Lam RY, Woo AY, Leung PS, Cheng CH: Antioxidant actions of phenolic compounds found in dietary plants on low-density lipoprotein and erythrocytes in vitro. J Am Coll Nutr 2007, 26:233-242.

20. Wallin B, Rosengren B, Shertzer HG, Camejo G: Lipoprotein oxidation and measurement of thiobarbituric acid reacting substances formation in a single microtiter plate: its use for evaluation of antioxidants. Anal Biochem 1993, 208:10-15.

21. Esterbauer $H$, Gebicki J, Puhl H, Jürgens $G$ : The role of lipid peroxidation and antioxidants in oxidative modification of LDL. Free Radic Biol Med 1992, 13:341-390.

doi:10.1186/1472-6882-14-3

Cite this article as: Seo et al: Simultaneous quantification and inhibitory effect on LDL oxidation of the traditional Korean medicine, Leejungtang. BMC Complementary and Alternative Medicine 2014 14:3. 